\section{Partners' anger mounts over NASA plans for space station}

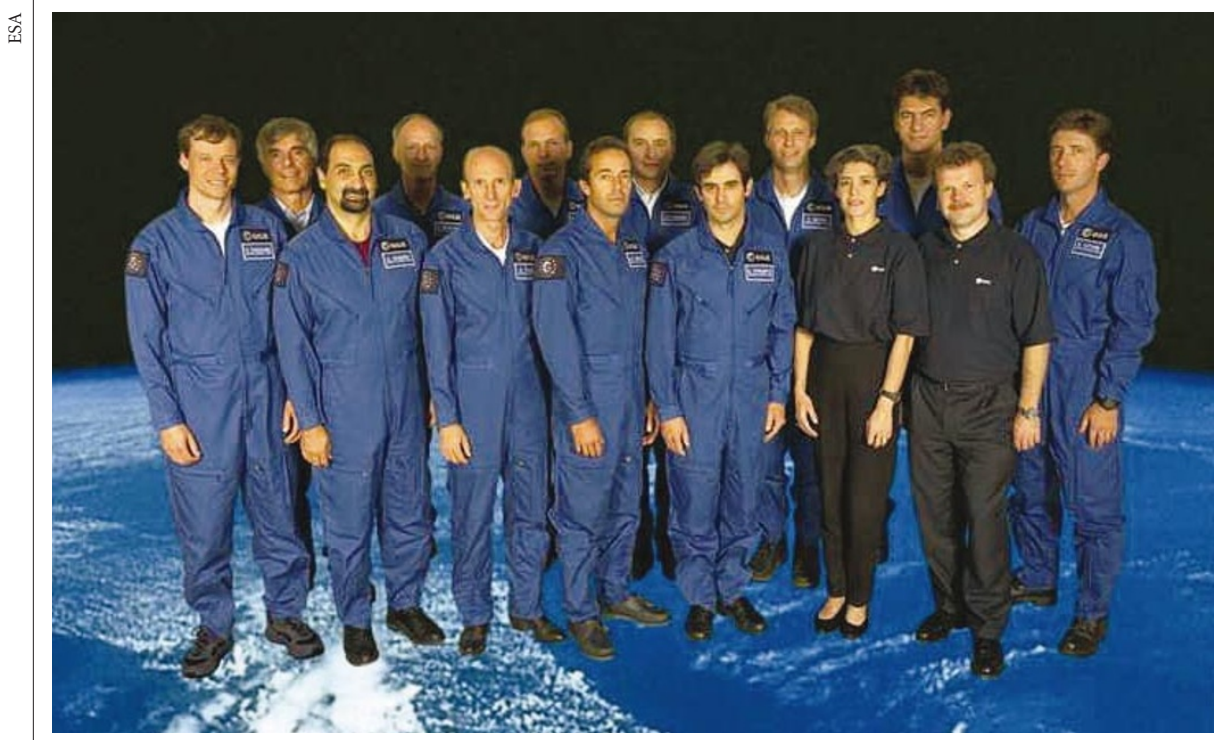

All dressed up, but nowhere to go? Space station cutbacks mean fewer European astronauts may fly.

Tony Reichhardt, Washington

The International Space Station's non-US partners arrived in Washington last week to vent their mounting anger at NASA's plan to trim back the project unilaterally. But it remains unclear what - if anything - they can do about it.

Representatives from Europe, Canada, Japan and Russia told NASA's advisory council that plans for the slimmed-down station now backed by the White House would not fulfil NASA's obligations under the international agreement to build and operate the station. The three-person, interim plan was sanctioned last month by a panel of US experts who reviewed the project (see Nature 414, 136; 2001).

Space officials from Europe and Canada have written to the US State Department complaining about the plan and stating that the international agreement on the station calls for any major changes in the design to be agreed by all the partners. At his senate confirmation hearing on 7 December, Sean O'Keefe, who has been nominated by President Bush to lead NASA, confessed to a "limited understanding" of NASA's legal obligations under the agreement, and said he would consult with the State Department on the matter.

But the partners told the quarterly meeting of the advisory council that the United States cannot renege on its agreement to provide living quarters and a "lifeboat" for a six- or seven-person crew - despite the fact that NASA faces cost overruns of at least $\$ 5$ billion on the project.

"We have had our financial problems, too," said Jörg Feustel-Büechl, director of manned spaceflight programmes for the European Space Agency. "We solved this problem at home, and we expect the same from you."

He added that European science ministers had "serious doubts" about continuing with the project after reports of US cutbacks - and that even a two-year delay before committing to the full station would be strongly opposed by Europe. A crew of three would have virtually no time to conduct research, and far fewer non-US astronauts could fly.

But with little real leverage to force NASA's hand, the partners fell back on the familiar line that the situation will damage collaboration on unspecified future projects. "There is much more at stake than just this programme," warned Feustel-Büechl.

Although the international agreement on the station calls for NASA to provide the living quarters and lifeboat, it also says that partners' obligations to the project depend on them actually obtaining funds from their respective governments.

The partners said they want a clear commitment from the US government to the full station. But a discussion among the advisory council members showed just how hard that might be to obtain. Some members argued that such a commitment, regardless of the final cost, would relieve any pressure on NASA to reform its management of the project.

At his confirmation hearing, meanwhile, O'Keefe said that NASA will have to "get our house in order" before committing to the full station.

\section{Europe's Mars mission to pay out for Beagle lander}

Sally Goodman, Paris

The European Space Agency (ESA) has been forced to allocate 36 million euros (US\$32 million) to a UK-designed lander to ensure that it is ready for launch as part of the Mars Express mission in 2003.

But members of ESA's Scientific Programme Committee, who agreed the extra funds on 4 December, said that no more money will be made available for the lander, which is called Beagle 2. They added that Mars Express - Europe's first mission to the red planet - will fly with or without the lander.

Beagle 2, which will search for organic material on Mars, was a late addition to Mars Express and costs for it were not included in the original budget of 150 million euros, which was finalized in 1996. The Beagle 2 consortium, led by Colin Pillinger of the Open University in Milton Keynes, England, was given the go-ahead to join the mission in 1998, provided it could raise sufficient funds. The consortium has since raised enough money from the British government, industry and private sponsorship deals to build the lander and its instruments.

But the inclusion of Beagle 2 is adding costs to the mission itself, such as those associated with keeping the lander in sterile conditions during the journey to Mars. ESA officials say they had expected to contribute something towards these, but that technical problems have increased the amount the agency will need to spend.

"We are doing everything we can to support Beagle 2," says Marcello Coradini, ESA's programme coordinator for Solar System missions.

Beagle 2's soft-landing system, which is made up of three gas-filled airbags, was responsible for the latest hitch. One or more of the airbags burst on inflation during tests last month at NASA's Plum Brook facility in Sandusky, Ohio. Such setbacks are delaying the lander's incorporation into the project, raising ESA's costs.

Pillinger remains confident that the project is on track, and points out that NASA needed extensive testing for the airbag system on Pathfinder, a craft that successfully landed on Mars in 1997. "We have a five-month contingency in our testing schedule for the airbags and plenty of time to adjust the design," he says. 